1871

\title{
КОНСОРТЫ БРЮХОНОГОГО МОЛЛЮСКА RAPANA VENOSA (VALENCIENNES, 1846) В СЕВЕРНОЙ ЧАСТИ ЧЁРНОГО МОРЯ. ЧACTЬ V: ANNELIDA (POLYCHAETA)
}

\author{
(ㄱ) 2021 г. . И. Бондарев, Н. А. Болтачева \\ ФГБУН ФИЦ «Институт биологии южных морей имени А. О. Ковалевского РАН», \\ Севастополь, Российская Федерация \\ E-mail: igor.p.bondarev@gmail.com
}

Поступила в редакцию 28.01.2020; после доработки 08.04.2020;

принята к публикации 04.06.2021; опубликована онлайн 16.06.2021.

Изучение таксоцена Annelida (Polychaeta), эпибионтов брюхоногого моллюска - вселенца Rapana venosa, продолжает цикл по описанию состава консорции самого крупного брюхоногого моллюска черноморского бентоса. Консорция $R$. venosa до сих пор является мало исследованной и неучтённой компонентой в структуре биоценозов шельфа Чёрного моря. Цель данной работы - изучить комплекс полихет консорции $R$. venosa. Задачи этого этапа: составление списка таксонов Annelida (Polychaeta) - эпибионтов рапаны; изучение биогеографической и трофической структуры таксоцена; исследование экологических связей полихет с ядром консорции. Для изучения консортного сообщества рапаны были осуществлены сборы в семи районах северной части Чёрного моря: 1 - Мамайя, Румыния; 2 - северо-западная часть Чёрного моря, Крымский сектор; 3 - Севастополь; 4 - Алупка; 5 - Ялта - Алушта; 6 - Карадаг; 7 Керченский пролив. Сбор $R$. venosa в прибрежной зоне до глубины 15 м проводили тотально с использованием легководолазного оборудования, в более глубоководной зоне (до 40 м) дночерпателем «Океан-50» с борта НИС «Профессор Водяницкий». Каждый экземпляр (пробу) рапаны помещали в отдельный пластиковый пакет с указанием района, глубины и биотопа. Всего отобрано и проанализировано 2411 проб, из них 977 — скальной рапаны и 1434 песчаной. Покрытие эпибионтами раковины $R$. venosa (интенсивность обрастания) оценивали в процентах от общей площади внешней поверхности раковины. Таксоцен Polychaeta консорции $R$. venosa включает 31 вид, представляющий 31 род 15 семейств 2 подклассов. Бо́льшая часть видов (18) относится к Errantia, половину из них составляют представители семейств Nereididae и Syllidae. K Sedentaria относятся 13 видов; наибольшее их количество (4) принадлежит семейству Serpulidae. Таксоцен Polychaeta консорции рапаны представлен тремя биогеографическими группами: аборигенные виды средиземноморско-атлантического генезиса (84 \%), эндемики Чёрного моря (10\%) и современные виды-вселенцы различного географического генезиса (6\%). На песчаной рапане обнаружен 31 вид полихет, а на скальной — только 5. Показатели развития фауны полихет значительно различаются по глубинам и районам исследований. Наиболее разнообразны полихеты в бухтах г. Севастополя (район № 3) на глубинах 2-10 м; максимальная глубина обнаружения полихет $(40$ м) соответствует наибольшей глубине отбора рапаны. Площадь покрытия раковины рапаны полихетами достигает 70 \%, встречаемость в отдельных районах составляет до $95 \%$. Максимальное число видов, обнаруженных на отдельном экземпляре рапаны, -8 ; в среднем на особях $R$. venosa отмечено 2-4 вида полихет. Таксономическое разнообразие и обилие Polychaeta определяют их значимость в консорции $R$. venosa. Благодаря инвазионному хищному моллюску $R$. venosa полихеты получают дополнительные возможности для распространения на шельфе Чёрного моря.

Ключевые слова: консорция, Polychaeta, Rapana venosa, Чёрное море, экология, эпибионты 
Изучение таксоцена Annelida (Polychaeta), эпибионтов брюхоногого моллюска - вселенца Rapana venosa (Valenciennes, 1846), является продолжением цикла работ по описанию консорции этой самой крупной гастроподы Чёрного моря. В предыдущих частях цикла рассмотрены представители шести типов животных: Cnidaria, Bryozoa, Porifera, Chordata (Бондарев и Ревков, 2017a), Mollusca (Bivalvia, Gastropoda, Polyplacophora) (Бондарев и Ревков, 2017b, 2018) и Arthropoda (Chelicerata: Arachnida; Crustacea: Malacostraca, Hexanauplia) (Бондарев и Бондаренко, 2019). В общей сложности в консорции рапаны установлено 64 вида зообентоса, принадлежащих перечисленным высшим таксонам; их список продолжает расширяться благодаря новым исследованиям. В консорции выявлено 65 видов макроводорослей обрастателей рапаны; плотность их покрытия может достигать 100 \% поверхности раковины (Bondarev \& Milchakova, 2018).

Ранее проведённые исследования показали, что экологическая роль $R$. venosa не сводится только к хищничеству (Бондарев и Ревков, 2017a, b, 2018 ; Бондарев и Бондаренко, 2019 ; Емельянов и др., 2010 ; Bondarev \& Milchakova, 2018 ; Savini et al., 2004). Довольно крупная раковина рапаны служит твёрдым субстратом для седентарных организмов. На раковине может формироваться комплекс организмов различных таксономических групп, связанных между собой топически и трофически. Такую естественно сложившуюся систему разнородных организмов, которые в течение всей жизни или хотя бы на некоторых фазах жизненного цикла находятся в тесных контактных отношениях и взаимно (или односторонне) зависят друг от друга, можно определить как консорцию, в которой $R$. venosa является ядром. Довольно широкое распространение и высокая численность рапаны во многих районах северной части Чёрного моря диктуют необходимость изучения и учёта вклада её консортов в общую структуру биоразнообразия экосистем бентали (Бондарев и Ревков, 2017a, b, 2018 ; Бондарев и Бондаренко, 2019 ; Емельянов и др., 2010 ; Bondarev \& Milchakova, 2018).

Вслед за существенным сокращением в 1990-2000-х гг. на скалах поселений Mytilus galloprovincialis (Lamarck, 1819) (Болтачева и др., 2015) - одного из основных объектов питания $R$. venosa - зарегистрировано и значительное уменьшение на скалах численности рапаны (Бондарев, 2010 ; Bondarev, 2014). Большинство современных локальных популяций $R$. venosa обитает на рыхлых грунтах (Бондарев, 2010, 2016). В биотопе рыхлых грунтов с рапаной связано наличие мобильных оазисов прикреплённых форм зоо- и фитобентоса, сформированных на поверхности раковины моллюска (Бондарев и Ревков, 2017a, b ; Бондарев и Бондаренко, 2019 ; Емельянов и др., 2010 ; Bondarev \& Milchakova, 2018 ; Savini et al., 2004). Ранее проведёнными исследованиями установлено, что наибольшее видовое разнообразие эпибионтов, а также максимальные степени покрытия ими раковин присущи рапане, обитающей на рыхлых грунтах (Бондарев и Ревков, 2017a, b ; Бондарев и Бондаренко, 2019 ; Емельянов и др., 2010 ; Bondarev \& Milchakova, 2018), поэтому в данной работе наибольшее внимание уделено исследованию именно этой экологической группы $R$. venosa. По принадлежности к одной из экологических групп рапану принято условно разделять на скальную и песчаную (Savini et al., 2004). Мы также используем для краткости эти определения, относя к песчаной рапане и особей, обитающих на других типах рыхлых грунтов.

Наличие полихет на поверхности раковин моллюсков как значимого компонента обрастаний отмечено давно (Зернов, 1913). Присутствие полихет на раковинах рапаны указано как для Средиземного моря (Savini et al., 2004), так и для Чёрного (Емельянов и др., 2010), однако во всех случаях речь шла исключительно о седентарных формах, строящих известковую трубку. Применённая нами методика сбора образцов в застегивающиеся пластиковые пакеты позволила более полно учесть седентарные и впервые обнаружить эррантные (бродячие) формы, которые преобладают по числу видов. 
Консорция $R$. venosa всё ещё является мало изученной компонентой в структуре биоценозов шельфа Чёрного моря, её исследование продолжается. Целью данной работы было изучить комплекс Annelida (Polychaeta) консорции R. venosa. Задачи этапа: составление списка таксонов полихет - эпибионтов рапаны, а также исследование биогеографической и трофической структуры таксоцена, распределения по районам и глубинам и экологических связей полихет с ядром консорции.

\section{МАТЕРИАЛ И МЕТОДЫ}

Сбор образцов и натурные исследования эпибионтов раковин $R$. venosa проведены в 2007-2018 гг., с июня по ноябрь, в семи районах северной части Чёрного моря (рис. 1, табл. 1).

Таблица 1. Районы исследований в северной части Чёрного моря и показатели суммарной площади покрытия зооконсортами поверхности раковин $R$. venosa, \% (мин.-макс. / среднее значение)

Table 1. Research areas in the northern Black Sea and indicators of $R$. venosa shell surface total coverage with zooconsorts, \% (min.-max. / mean value)

\begin{tabular}{|c|l|c|c|c|c|c|}
\hline \multirow{2}{*}{$№$} & \multicolumn{1}{|c|}{ Район } & Кол-во проб & Глубина, м & Месяц, год & Грунт & $\begin{array}{c}\text { Покрытие, } \\
\text { \%оверхности }\end{array}$ \\
\hline 1 & Пляж Мамайя & 12 & $0-1,5$ & XI, 2008 & песок & $2-35 / 5$ \\
\hline \multirow{2}{*}{2} & $\begin{array}{l}\text { Северо-западная } \\
\text { часть Чёрного моря }\end{array}$ & 11 & $19,5-25,0$ & X-XI, 2010 & $\begin{array}{c}\text { ил } \\
\text { с ракушей }\end{array}$ & $0-5 / 2$ \\
\hline \multirow{2}{*}{3} & Севастополь & 1250 & $2-10$ & VI-IX, 2015, 2018 & песок & $0-100 / 35$ \\
\cline { 2 - 7 } & 130 & $1,5-4$ & VI-IX, 2015, 2018 & скала & $0-60 / 25$ \\
\hline 4 & Алупка & 125 & $0,5-5,5$ & IX, 2016, 2018 & скала & $0-30 / 10$ \\
\hline 5 & Ялта - Алушта & 2 & $34 ; 40$ & X-XI, 2010 & ил & $20 ; 25$ \\
\hline \multirow{2}{*}{6} & \multirow{2}{*}{ Карадаг } & 722 & $3-10$ & VI-VII, 2007, 2009 & скала & $0-70 / 30$ \\
\hline 7 & Керчь & 14 & $21,8-23$ & X-XI, 2010 & песчаный ил & $5-85 / 30$ \\
\hline
\end{tabular}

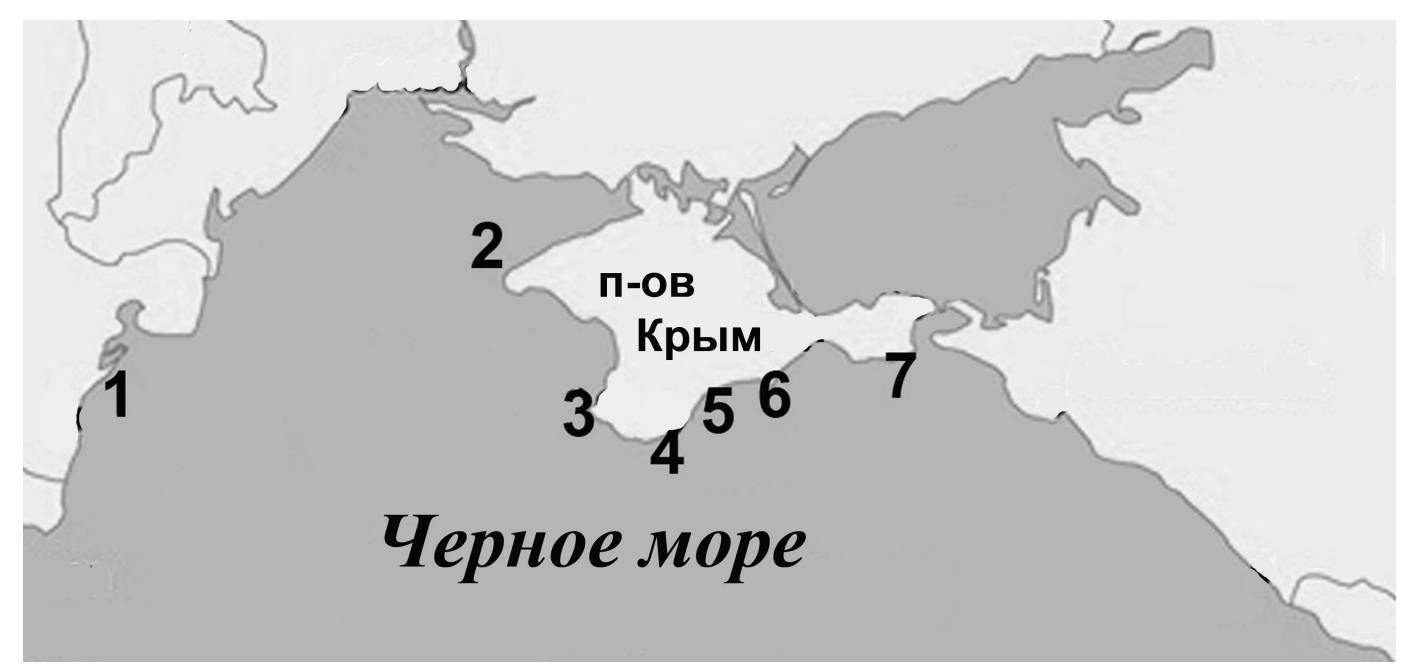

Рис. 1. Карта районов отбора проб: 1 - пляж Мамайя (Румыния); 2 - северо-западная часть Чёрного моря, Крымский сектор; 3 - Севастополь; 4 - Алупка; 5 - Ялта - Алушта; 6 - Карадаг; 7 - Керченский пролив

Fig. 1. Sampling map: 1 - Mamaia Beach (Romania); 2 - northwestern Black Sea, Crimea offshore; 3 - Sevastopol; 4 - Alupka; 5 - Yalta - Alushta; 6 - Karadag; 7 - Kerch Strait 
На глубинах до 15 м сбор особей $R$. venosa проводили безвыборочно вручную с использованием легководолазного снаряжения. Каждый экземпляр рапаны с эпибионтами (пробу) помещали в отдельный пластиковый пакет с указанием глубины и биотопа. В более глубоководной зоне сбор материала проводили с помощью дночерпателя «Океан-50» с борта НИС «Профессор Водяницкий» (рейс № 68, 2010 г.). Всего отобрано и проанализировано 2411 экземпляров $R$. venosa, из них 977 - скальной рапаны и 1434 - рапаны рыхлых грунтов. Размер исследованных особей $R$. venosa варьировал от 31,3 до 110,8 мм (средний - 54,4 мм), возраст - от 1 до 12 лет (средний - 4 года). Покрытие эпибионтами раковины рапаны (интенсивность обрастания) оценивали в процентах от общей площади внешней поверхности раковины (Бондарев и Ревков, 2017а).

Обобщённая характеристика встречаемости таксонов в сводной таблице (см. табл. 2) дана по следующей шкале: «-» — таксон в выборке моллюсков не обнаружен; «+» — встречается редко (до $1 \%$ выборки); «++» — нечасто (2-10\%); «+++» — часто (11-30\%); «++++» — очень часто (> 30 \%). Линейные размеры особей рапаны измеряли штангенциркулем с точностью до 0,1 мм, полихет - с помощью окуляр-микрометра микроскопа МБС-10. Взвешивание объектов (сырая масса) исследования выполнено на электронных весах WLM-200: особей рапаны - с точностью до 0,1 г; полихет - до 0,0001 г. Трофическая специализация полихет приведена по (Киселева, 2004 ; Хлебович, 1996 ; Giangrande et al., 2004 ; Serrano et al., 2006).

\section{РЕЗУЛЬТАТЫ И ОБСУЖДЕНИЕ}

Список таксонов Polychaeta в консорции $R$. venosa включает 31 вид, представляющий 31 род 15 семейств. Бо́льшая часть видов (18) относится к Errantia, половину из них составляют представители семейств Nereididae и Syllidae. Из Sedentaria (13 видов) наибольшим количеством видов (4) представлено семейство Serpulidae (табл. 2).

Таблица 2. Список таксонов Polychaeta консорции $R$. venosa и их трофическая специализация, T (C - плотоядные; D - детритофаги; F - фильтраторы; Н - растительноядные; O - полифаги); встречаемость на раковинах моллюсков, обитающих на рыхлых (1) и скальных (2) грунтах, по глубинам и районам в соответствии с рис. 1

Table 2. List of Polychaeta taxa of $R$. venosa consortium and their trophic specialization, $\mathrm{T}(\mathrm{C}-$ carnivores; $\mathrm{D}$ - detritivores; $\mathrm{F}$ - filter feeders; $\mathrm{H}$ - herbivores; and $\mathrm{O}$ - omnivores); occurrence at shells of molluscs inhabiting loose (1) and rocky (2) sediments by depths and research areas according to Fig. 1

\begin{tabular}{|c|c|c|c|c|c|}
\hline \multirow{2}{*}{ Таксон } & \multirow{2}{*}{$\mathrm{T}$} & \multicolumn{2}{|c|}{ Встречаемость } & \multirow{2}{*}{ Глубина, м } & \multirow{2}{*}{ Районы } \\
\hline & & 1 & 2 & & \\
\hline \multicolumn{6}{|l|}{ Errantia } \\
\hline \multicolumn{6}{|l|}{ Phyllodocidae Örsted, 1843} \\
\hline Mysta picta (Quatrefages, 1865) & $\mathrm{C}$ & + & - & $2,0-5,0$ & 3 \\
\hline Eulalia viridis (Linnaeus, 1767) & $\mathrm{C}$ & + & - & $2,5-8,0$ & 3 \\
\hline Genetyllis tuberculata (Bobretzky, 1868) & $\mathrm{C}$ & + & - & $2,0-6,0$ & 3 \\
\hline \multicolumn{6}{|l|}{ Polynoidae Kinberg, 1856} \\
\hline Harmothoe imbricata (Linnaeus, 1767) & $\mathrm{C}, \mathrm{O}$ & + & - & $2,5-6,0$ & 3 \\
\hline \multicolumn{6}{|l|}{ Pholoidae Kinberg, 1858} \\
\hline Pholoe inornata Johnston, 1839 & $\mathrm{O}$ & + & - & $3,0-10,0$ & 3 \\
\hline \multicolumn{6}{|l|}{ Nereididae Blainville, 1818} \\
\hline Alitta succinea (Leuckart, 1847) & $\mathrm{D}, \mathrm{O}$ & + & - & $3,0-6,0$ & 3 \\
\hline Hediste diversicolor (O. F. Müller, 1776) & $\mathrm{O}, \mathrm{H}$ & + & - & $3,0-10,0$ & 3,7 \\
\hline Nereis zonata Malmgren, 1867 & $\mathrm{D}, \mathrm{H}$ & + & - & $3,0-6,0$ & 3 \\
\hline Perinereis cultrifera (Grube, 1840$)$ & $\mathrm{H}, \mathrm{D}$ & ++ & - & $2,5-10$ & 3 \\
\hline Platynereis dumerilii (Audouin \& Milne Edwards, 1833) & $\mathrm{H}, \mathrm{O}$ & +++ & - & $2,0-10$ & $3,6,7$ \\
\hline
\end{tabular}

Продолжение на следующей странице... 


\begin{tabular}{|c|c|c|c|c|c|}
\hline \multirow{2}{*}{ Таксон } & \multirow{2}{*}{$\mathrm{T}$} & \multicolumn{2}{|c|}{ Встречаемость } & \multirow{2}{*}{ Глубина, м } & \multirow{2}{*}{ Районы } \\
\hline & & 1 & 2 & & \\
\hline \multicolumn{6}{|l|}{ Syllidae Grube, 1850} \\
\hline Exogone naidina Örsted, 1845 & $\mathrm{H}$ & + & - & 4,5 & 3 \\
\hline Salvatoria clavata (Claparède, 1863) & $\mathrm{O}$ & + & - & $2,0-6,0$ & 3 \\
\hline Syllis gracilis Grube, 1840 & $\mathrm{O}$ & + & - & 3,$0 ; 6,0$ & 3 \\
\hline Trypanosyllis zebra (Grube, 1860$)$ & $\mathrm{D}$ & + & - & 4,0 & 3 \\
\hline \multicolumn{6}{|l|}{ Pilargidae Saint-Joseph, 1899} \\
\hline Sigambra tentaculata (Treadwell, 1941) & $\mathrm{C}, \mathrm{D}$ & + & - & 5,5 & 3 \\
\hline \multicolumn{6}{|l|}{ Eunicidae Berthold, 1827} \\
\hline Eunice vittata (Delle Chiaje, 1828) & $\mathrm{C}$ & + & - & $2,5-7,0$ & 3 \\
\hline Lysidice ninetta Audouin \& H. Milne Edwards, 1833 & $\mathrm{D}$ & + & - & $2,5-6,0$ & 3 \\
\hline \multicolumn{6}{|l|}{ Dorvilleidae Chamberlin, 1919} \\
\hline Protodorvillea kefersteini (McIntosh, 1869) & $\mathrm{O}$ & + & - & 4,5 & 3 \\
\hline \multicolumn{6}{|l|}{ Sedentaria } \\
\hline \multicolumn{6}{|l|}{ Orbiniidae Hartman, 1942} \\
\hline Naineris laevigata (Grube, 1855$)$ & $\mathrm{D}$ & + & - & 4,0 & 3 \\
\hline \multicolumn{6}{|l|}{ Spionidae Grube, 1850} \\
\hline Polydora sp. & $\mathrm{D}$ & ++ & + & $0,5-12,0$ & $3,5,6,7$ \\
\hline Prionospio cirrifera Wirén, 1883 & $\mathrm{D}$ & + & - & 6,0 & 3 \\
\hline Spio decorata Bobretzky, 1870 & $\mathrm{D}$ & + & - & 4,5 & 3 \\
\hline \multicolumn{6}{|l|}{ Opheliidae Malmgren, 1867} \\
\hline Polyophthalmus pictus (Dujardin, 1839) & $\mathrm{D}$ & ++ & + & $2,0-5,0$ & $3,6,7$ \\
\hline \multicolumn{6}{|l|}{ Capitellidae Grube, 1862} \\
\hline Capitella capitata (Fabricius, 1780) & $\mathrm{D}$ & + & - & 5,0 & 3 \\
\hline \multicolumn{6}{|l|}{ Sabellariidae Johnston, 1865} \\
\hline Sabellaria taurica (Rathke, 1837) & $\mathrm{F}$ & + & - & $4,0-8,0$ & 3,7 \\
\hline \multicolumn{6}{|l|}{ Terebellidae Johnston, 1846} \\
\hline Amphitritides gracilis (Grube, 1860$)$ & $\mathrm{D}$ & + & - & 4,5 & 3 \\
\hline Polycirrus jubatus Bobretzky, 1869 & $\mathrm{D}$ & + & - & 4,0 & 3 \\
\hline \multicolumn{6}{|l|}{ Serpulidae Rafinesque, 1815} \\
\hline Hydroides dianthus (Verrill, 1873) & $\mathrm{F}$ & ++ & - & $2,0-8,0$ & 3,7 \\
\hline Spirobranchus triqueter (Linnaeus, 1758) & $\mathrm{F}$ & ++++ & +++ & $0,5-40,0$ & $1,2,3,4,5,6,7$ \\
\hline \multicolumn{6}{|l|}{ Spirorbinae Chamberlin, 1919} \\
\hline Janua heterostropha (Montagu, 1803) & $\mathrm{F}$ & ++++ & ++++ & $0,5-23,0$ & $1,2,3,4,5,6,7$ \\
\hline Pileolaria militaris Claparède, 1870 & $\mathrm{~F}$ & +++ & +++ & $1,0-8,0$ & $3,4,6,7$ \\
\hline
\end{tabular}

Ранее в консорции $R$. venosa было зафиксировано 64 вида зообентоса, относящихся к шести типам: Cnidaria, Bryozoa, Porifera, Chordata, Mollusca и Arthropoda (Бондарев и Ревков, 2017a, b ; Бондарев и Бондаренко, 2019 ; Емельянов и др., 2010). Наибольшим количеством таксонов был представлен тип Arthropoda (27 видов) (Бондарев и Бондаренко, 2019). По нашим данным, класс Polychaeta, включающий 31 вид, - таксономически самая разнообразная группа зооконсортов рапаны.

Предшествующими исследованиями консортов рапаны в Чёрном море (Емельянов и др., 2010) установлены только два вида полихет - Spirobranchus triqueter и Janua heterostropha. В списке эпибионтов скальной и песчаной рапаны Адриатического моря из полихет также приведены только серпулиды без указания их видовой принадлежности (Savini et al., 2004). Полихет-перфораторов Polydora ciliata (Johnston, 1838) и Polydora websteri Hartman in Loosanoff \& Engle, 1943 отмечали в раковинах устриц Magallana gigas (Thunberg, 1793), выращиваемых 
в марихозяйствах в Чёрном море (Гаевская и Лебедовская, 2010 ; Лисицкая и др., 2010), однако в раковинах $R$. venosa представителей этого рода ранее не диагностировали. Таким образом, наши исследования значительно расширяют представления о биоразнообразии таксоцена полихет консортных $R$. venosa.

Биогеографическая характеристика таксоцена. Фауна полихет, обнаруженных в консорции $R$. venosa, состоит из трёх биогеографических групп: аборигенных видов средиземноморскоатлантического происхождения, эндемичных видов Чёрного моря и современных вселенцев различного географического генезиса. Таксоцен полихет консорции преимущественно (25 видов, примерно 84 \%) представлен видами средиземноморско-атлантического происхождения. Эти виды, ставшие постоянными компонентами фауны, имеют в Черноморском бассейне аборигенный статус.

Эндемиками Чёрного моря являются три вида ( $10 \%$ общего количества видов) - Genetyllis tuberculata (рис. 2A), Sabellaria taurica и Polycirrus jubatus.

Два вида ( 6 \%) являются современными вселенцами - Sigambra tentaculata и Hydroides dianthus. Единственный представитель семейства Pilargidae и рода Sigambra Müller, 1858 в Чёрном море, S. tentaculata, впервые был указан для побережий Крыма и Кавказа на глубине 5-40 м на ракушечнике и илисто-ракушечном грунте в 1964 г. (Киселева, 2004). Типовое местообитание этого вида - Атлантическое побережье Северной Америки (Новая Англия), однако в настоящее время он найден в морях Средиземноморского бассейна, у побережья Европы (Giangrande et al., 2004). В наших сборах S. tentaculata (длина - 7,0 мм, масса - 0,002 г) обнаружена один раз в бухте Голубая (г. Севастополь, Крым) на глубине 6 м на песчаной рапане.

Серпулиду $H$. dianthus относят к опасным инвазионным видам, в настоящее время активно распространяющимся в различные районы Мирового океана (Sun et al., 2017). Первоначально вид был описан для Атлантического побережья Северной Америки, позже обнаружен в Мексиканском заливе, у берегов Европы и Западной Африки, в Средиземном море, а затем - у берегов Южной Америки, Японии и Китая (Çinar et al., 2014 ; World Polychaeta database, 2019 ; Sun et al., 2017). Одни исследователи считали H. dianthus вселенцем в Средиземное море, другие - криптогенным видом (Streftaris \& Zenetos, 2006). В Чёрном море этот вид впервые был зарегистрирован в 2009 г. на устрицах Magallana gigas, выращиваемых в бухте Казачья (Севастополь), а впоследствии - и в обрастании камней и мидийных коллекторов в бухте Севастопольская (Болтачева и др., 2011). Детальные генетические исследования $H$. dianthus из разных районов Мирового океана показали, что черноморские экземпляры наиболее близки к особям из Мексиканского залива (Техас, США) и были интродуцированы в Чёрное море напрямую из американской популяции (Sun et al., 2017). Нами H. dianthus в наибольшем количестве обнаружен в бухте Казачья (район № 3).

В целом таксоцен полихет консорции $R$. venosa по биогеографическому делению в общих чертах совпадает со структурой их фауны в Чёрном море. В определённой степени наличие рапаны способствует сохранению и распространению эндемичных полихет и видов-вселенцев.

Показатели развития таксоцена по биотопам и районам. На песчаной рапане нами обнаружен 31 вид, а на скальной - только 5 видов, относящихся к Sedentaria (табл. 2). Аналогична ситуация и по другим показателям развития полихет - встречаемости и численности. Они в целом, по нашим данным, выше у песчаной рапаны, хотя могут значительно различаться по районам исследований. Максимальные площадь покрытия полихетами (70 \%) и их встречаемость (до $95 \%$ ) отмечены на песчаной рапане (район № 3), однако минимальные значения этих показателей (до 5 \%) также зарегистрированы у рапаны, обитающей на рыхлых грунтах (районы № 1 и 2). 


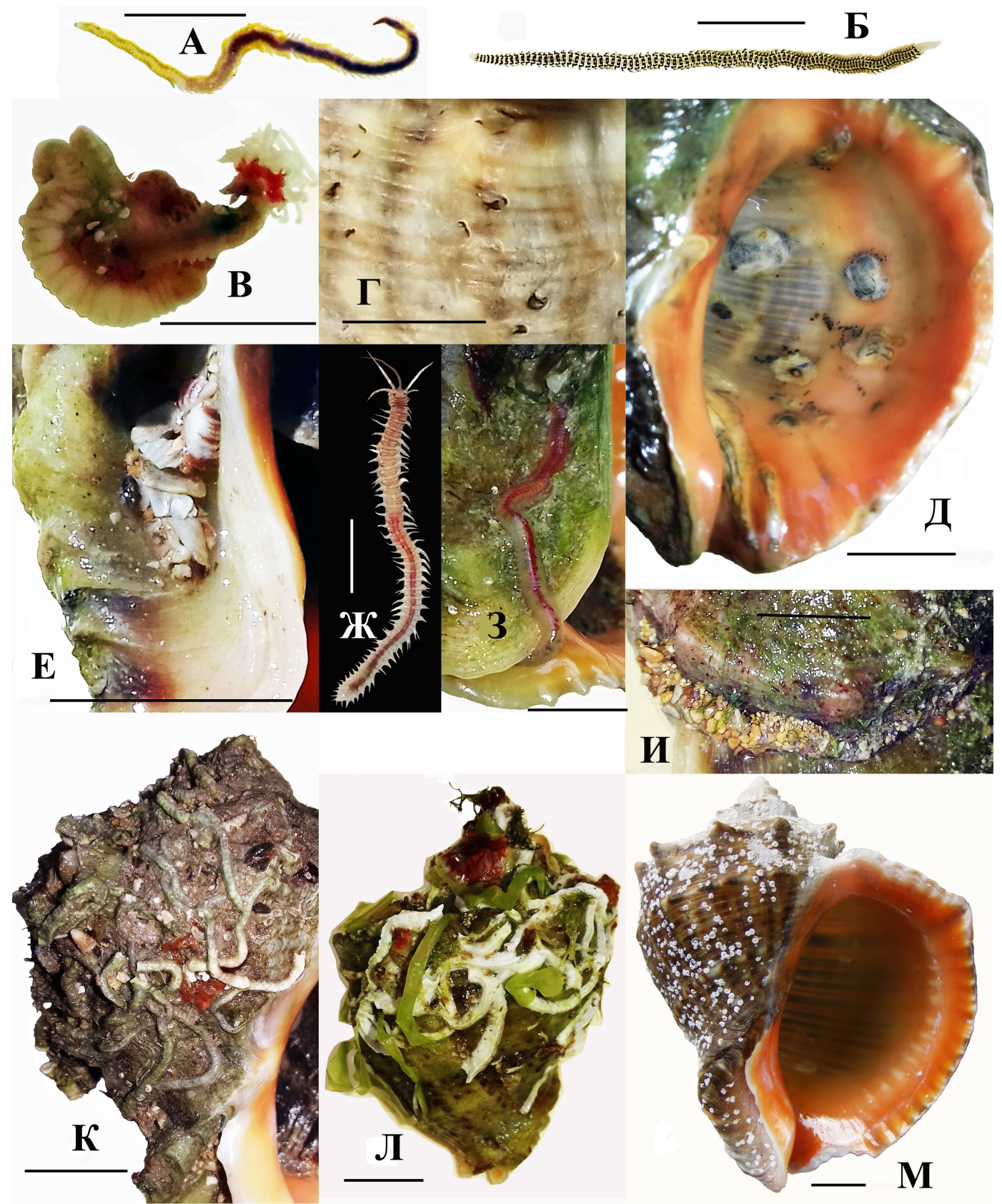

Рис. 2. Полихеты консорции R. venosa: А - Genetyllis tuberculata; Б - Mysta picta; В - Amphitritides gracilis; Г — выходные отверстия Polydora sp. на очищенной от обрастателей поверхности раковины рапаны; Д - блистеры в устье раковины, перекрывающие ходы Polydora sp.; Е - инкрустированная обломками раковин моллюсков кожистая трубка, выходящая из полости пупка раковины рапаны; Ж - Eunice vittata; 3 - E. vittata, выползший из полости пупка раковины рапаны; И - песчаная трубка Sabellaria taurica, расположенная на шве оборотов раковины рапаны; К-М - известковые трубки серпулид на поверхности раковины рапаны (К - Hydroides dianthus; Л — Spirobranchus triqueter; M - Janua heterostropha). Масштабные линии - $1 \mathrm{~cm}$

Fig. 2. Polychaetes of $R$. venosa consortium: A - Genetyllis tuberculata; Б - Mysta picta; B - Amphitritides gracilis; $\Gamma$ - Polydora sp. boring on a shell surface cleaned from fouling; Д - blisters at the shell mouth blocking Polydora sp. passages; E - leathery tube encrusted with mollusc shell fragments, protruding from the umbilical cavity of the rapa whelk shell; $Ж$ - Eunice vittata; $3-E$. vittata crawled out of the umbilical cavity of the rapa whelk shell; $И$ - Sabellaria taurica sand tube located on the whorl suture of the rapa whelk shell; K-M - calcareous tubes of serpulids on the rapa whelk shell surface ( $\mathrm{K}$ - Hydroides dianthus; Л - Spirobranchus triqueter; M - Janua heterostropha). Scale bars are $1 \mathrm{~cm}$ 
Наиболее высокие показатели характерны для бухт г. Севастополя (район № 3), где зафиксированы все виды полихет консорции; это отчасти может быть связано с тем, что в данном районе было отобрано большее, чем в других районах, количество проб. Основной причиной, очевидно, являются благоприятные условия в бухтах: умеренная динамика вод не препятствует развитию комплекса эпибионтов рапаны.

Наибольшая встречаемость полихет в целом отмечена для спирорбин $J$. heterostropha и P. militaris (в бухте Казачья она достигала 90 \%). Второе место по встречаемости (в отдельных районах - до $75 \%$ ) принадлежало серпулиде $S$. triqueter, а в бухте Казачья - вселенцу H. dianthus. Оба этих вида могут совместно присутствовать на одном экземпляре рапаны (районы № 3 и 7). Следующие по встречаемости (представители Sedentaria, Polydora sp. и P. pictus) обнаружены значительно реже (у 2-10 \% рапан). Отметим, что на глубинах 0,5-2,0 м в районе г. Керчи (район № 7) полидорой поражены до $90 \%$ особей $R$. venosa.

Из Errantia наиболее часто встречающимися видами являются P. dumerilii и P. cultrifera, их встречаемость в бухте Казачья - 30 и $10 \%$ соответственно. Ряд видов обнаружены в консорции единично (1-5 экз. за всё время исследований): A. gracilis, C. capitata, M. picta, N. laevigata, $N$. zonata, P. jubatus, P. cirrifera, P. kefersteini, S. decorata и T. zebra. В количестве 6-10 экз. зарегистрированы E. viridis, H. imbricata, L. ninetta и S. gracilis. Общее количество видов полихет, чья встречаемость не превышает $1 \%$, составляет 23 (74 \% общего числа).

Количество полихет на отдельном экземпляре рапаны даже в одном районе варьирует в очень широких пределах (от 1 до 132 экз.) в случае присутствия серпулид, и особенно спирорбин. Максимальное количество особей полихет зарегистрировано на рапане 4-летнего возраста (высота 71,5 мм) из района № 3. При этом в том же районе на особях более старшего возраста, до 12 лет, обнаружено значительно меньшее количество полихет (12-48 экз.). В районах № 1 и 2 значения показателей развития фауны полихет у рапан всех возрастов и размеров минимальны. Поскольку подавляющее большинство полихет консорции рапаны живут около года, их конкурентные возможности ниже, чем у многолетних организмов, которые способны расширять своё присутствие в течение длительного времени. Для таких массовых седентарных форм, как серпулиды, важно, чтобы при оседании личинок имелось свободное пространство и были сформированы некоторые внешние условия для развития. К ним относятся особенности гидрофизики и литодинамики в районе, их межгодовые и сезонные изменения, конкурентная борьба с другими эпибионтами, выедание хищниками и др. Такая многофакторность и особенности биологии приводят к тому, что естественная тенденция на увеличение присутствия эпибионтов по мере увеличения площади поверхности раковины в процессе роста рапаны (Бондарев и Ревков, 2017a, b, 2018 ; Бондарев и Бондаренко, 2019 ; Bondarev \& Milchakova, 2018) для полихет не прослеживается.

Максимальное число видов, обнаруженных на отдельном экземпляре рапаны, - 8 . Обычно на особях $R$. venosa присутствует 2-4 вида полихет. Размер полихет в консорции варьировал от 0,5 мм (молодь J. heterostropha и P. militaris) до 61,5 мм (A. gracilis) (средний — 6,2 мм), а масса изменялась от 0,0001 до 0,017 г (средняя - 0,0012 г). Площадь покрытия поверхности раковины рапаны полихетами может достигать $70 \%$, а масса полихет - 0,021 г, что составляет не более 0,03\% массы моллюска - ядра консорции. Масса других эпибионтов рапаны, например Bivalvia, может быть сопоставима с массой самого моллюска (Бондарев и Ревков, 2017b). Следовательно, полихеты вносят незначительный вклад в биомассу консорции $R$. venosa.

Табл. 2 показывает, что количество видов полихет консорции $R$. venosa значительно различается в зависимости от того, в каком биотопе обитает рапана (ядро консорции), что аналогично присутствию других эпибионтов на рапане. Число видов, встречаемость, численность и биомасса эпибионтов других таксономических групп на песчаной рапане в большинстве исследованных нами районов выше таких же показателей для скальной рапаны (Бондарев и Ревков, 2017a, b, 2018 ; 
Бондарев и Бондаренко, 2019 ; Bondarev \& Milchakova, 2018). Между тем показатели развития фауны полихет значительно различаются по районам: как минимальные, так и максимальные их значения зафиксированы нами для песчаной рапаны (табл. 2).

По данным исследований, предшествующих нашим, показатели развития эпибионтов $R$. venosa зависят скорее от района обитания рапаны, чем от принадлежности её к скальной или песчаной форме. Были обнаружены два вида серпулид, их встречаемость на песчаной рапане имела минимальные значения (0-2 \%), а на скальной $R$. venosa - максимальные (до $99 \%$ ) (Емельянов и др., 2010). Данные исследований консортов $R$. venosa из Адриатического моря показали, что частота встречаемости серпулид на скальной рапане значительно выше, чем на песчаной (93\% против $13 \%$ ) (Savini et al., 2004). Эти сведения по песчаной рапане соответствуют нашим лишь отчасти.

К сожалению, сравнение можно провести по встречаемости только серпулид. Другие виды полихет в консорции рапаны как в Чёрном море, так и в Адриатическом не зарегистрированы. Именно поэтому наши данные являются базовыми для дальнейших исследований таксоцена полихет консорции $R$. venosa.

Связь с ядром консорции. Представители Errantia и часть видов Sedentaria свободно перемещаются по поверхности раковины рапаны, укрываясь среди водорослевых обрастаний. Иногда их можно обнаружить среди яйцевых капсул рапаны, которые отложены на раковине или между особями зообентоса (преимущественно Bivalvia), обрастающими раковину $R$. venosa. Хищные полихеты семейства Phyllodocidae - E. viridis, G. tuberculata и M. picta (рис. 2Б) - могут укрываться в свёрнутых в трубку талломах зелёных водорослей Ulva spp. Не исключено, что эти полихеты сами создают из талломов водорослей вре́менные укрытия.

Как при наличии обрастаний, так и при их отсутствии полихеты предпочитают укрываться в естественных углублениях и полостях раковины. Такими углублениями являются пришовный канал оборотов раковины и пупочная полость, образующаяся при навивании оборотов раковины вокруг столбика. Глубина канала пупочной полости зависит от размера раковины рапаны и может превышать длину самой крупной полихеты из нашей выборки. В пупочной полости раковины рапаны высотой 102 мм из бухты Круглая (район № 3) был обнаружен экземпляр теребеллиды A. gracilis (рис. 2В) длиной 60,5 мм. Этот экземпляр покинул убежище при раздражении длинной иглой, однако зачастую извлечь полихету из узкой пупочной полости не представляется возможным либо удаётся только частично.

Углубления и полости на поверхности и в толще раковины рапаны могут появляться в результате сверления губкой Pione vastifica (Hancock, 1849) (Бондарев и Ревков, 2017а). В ходах, сформированных пионой, обнаружены L. ninetta, которые, по-видимому, их расширяют, обладая способностью перфорировать раковины моллюсков (Виноградов, 1949). Перфорировать раковины могут и полидорины. Для Чёрного моря известны два вида рода Polydora, обладающих этой способностью, - нативный $P$. ciliata и недавний вселенец $P$. websteri (Гаевская и Лебедовская, 2010). Количество Polydora sp., обнаруженных нами в раковинах живых $R$. venosa, достигало 26 особей на 1 экз. рапаны. На внешней поверхности раковины рапаны ходы червей имеют отверстия (рис. 2Г), позволяющие полидоре питаться, собирая детрит, и удалять продукты жизнедеятельности. Моллюски, защищаясь от раздражающего воздействия полихет, в местах их проникновения во внутренний слой раковины образуют блистеры (рис. 2Д). Ранее было показано, что P. ciliata предпочитает обитать в раковинах черноморских Tritia reticulata (Linnaeus, 1758), занятых раками-отшельниками, а Dipolydora armata (Langerhans, 1880) в Средиземном море преимущественно перфорирует либо пустые раковины гастроподы Stramonita haemastoma (Linnaeus, 1767) (Muricidae), либо раковины этого вида, занятые раками-отшельниками (Виноградов и Лосовская, 1968 ; Bick, 2006). 
Ряд видов червей обнаружен в кожистых трубках, зачастую инкрустированных песчинками и мелкими обломками раковин моллюсков (рис. 2Е): Eunice vittata (рис. 2Ж, 3), Lysidice ninetta, Perinereis cultrifera, Platynereis dumerilii. Чаще всего кожистые трубки с полихетами располагаются в вышеупомянутых углублениях и полостях, а их части, находящиеся на поверхности раковин рапаны, инкрустированы обломочным материалом (рис. 2Е). В большинстве таких трубок отмечен Platynereis dumerilii. Sabellaria taurica строит прочные песчаные трубки на внешней поверхности раковины рапаны (рис. 2И). Наиболее распространёнными являются известковые трубки серпулид (рис. 2К-М), которые могут покрывать до 70 \% поверхности раковины $R$. venosa.

Представляет интерес то, является ли связь полихет с ядром консорции случайной или экологически обусловленной. У многих Sedentaria тесная связь с рапаной определяется использованием раковины как субстрата для внедрения (Polydora sp.) или прикрепления прочных трубок (Sabellariidae, Serpulidae). Для Errantia эта связь гораздо менее очевидна и требует дополнительного рассмотрения.

Известно, что некоторые нереиды строят трубки. В гладких пергаментных трубках обитает Nicon moniloceras (Hartman, 1940), а пергаментные трубки Simplisetia erythraeensis (Fauvel, 1918) инкрустированы песчинками и частичками ржавого ила (Хлебович, 1996). В полупрозрачных трубках, прикреплённых к водорослям, камням или раковинам, обитают $P$. dumerilii и Platynereis bicanaliculata (Baird, 1863) (Хлебович, 1996). Нами на раковинах $R$. venosa в кожистых трубках, зачастую инкрустированных обломками раковин и песчинками, обнаружены не только Nereididae ( $P$. dumerilii и $P$. cultrifera), но и представители семейства Eunicidae ( $E$. vittata и L. ninetta). Элементы морфологии раковины $R$. venosa, прежде всего её пупок, полихеты используют для укрытия. Таким образом, ряд видов бродячих полихет имеет тесную связь с ядром консорции, используя раковину рапаны как субстрат.

Возможно, подвижные виды полихет могут укрываться от хищников среди водорослей и седентарных животных на раковине $R$. venosa; по-видимому, часть видов находит там пищу. Это прежде всего относится к растительноядным видам, таким как P. dumerilii и P. cultrifera, которых могут привлекать водорослевые обрастания рапан, но актуально и для видов, питающихся фауной, которая сопутствует водорослям, таких как P. pictus. Известно, что нереиды образуют большие скопления на мидиевых банках; причина этого - способность питаться псевдофекалиями моллюсков, что подтверждено экспериментально (Хлебович, 1996). На черноморских рапанах митилиды являются одними из наиболее распространённых обрастателей (Бондарев и Ревков, 2017b) и, соответственно, могут предоставлять пищу некоторым видам полихет. Кроме того, сама рапана, активно питаясь, на протяжении большей части года ежедневно производит фекалии. Прямых наблюдений за питанием полихет этими фекальными массами нет, однако такая трофическая связь не исключена.

Педальные железы рапаны обильно выделяют слизь, которая служит для защиты тела от внешних воздействий и для смазывания скользящей поверхности подошвы ноги при ползании. Наружные покровы рапаны секретируют мукус, представляющий собой смесь кислых и нейтральных мукополисахаридов или мукопротеинов. Помимо слизи, наружные покровы рапаны выделяют белковые секреты. При нападении рапаны на двустворчатых моллюсков мукус из гипобранхиальной железы в большом количестве проникает внутрь раковины жертвы (Чухчин, 1970). Мы наблюдали, как питающаяся рапана привлекала плотоядных моллюсков T. reticulata, которые окружали хищника по периметру раковины. Можно предположить, что в процессе перетирания жертвы радулой рапаны отдельные кусочки пищи попадают в воду, привлекая плотоядных представителей бентоса. Эти остатки, как и перечисленные вещества, выделяемые рапанами, вероятно, могут служить пищей полихетам. 
Таким образом, $R$. venosa не только является субстратом для многих полихет, но и привлекает разнообразные по типу питания виды, в результате чего формируются трофические цепи элементарного биоценоза рапаны.

Трофическая структура. Трофическая принадлежность видов полихет консорции $R$. venosa приведена в табл. 2. Для видов, которым присущ смешанный тип питания, в табл. 2 последовательность буквенных индексов дана в соответствии с преобладанием или типом, характерным для взрослых особей. Бо́льшая часть видов таксоцена (12 видов, $39 \%)$ - детритофаги. Далее по числу видов следуют плотоядные (6 видов, $19 \%$ ), фильтраторы и полифаги (по 5 видов, $16 \%$ ), растительноядные (3 вида, $10 \%)$.

По численности полихет трофическая структура таксоцена существенно отличается. Более $90 \%$ численности полихет консорции рапаны составляют фильтраторы, преимущественно серпулиды. Второе место по численности $(5,5 \%)$ занимают растительноядные или преимущественно растительноядные виды. При этом около $70 \%$ их численности приходится на $P$. dumerilii, взрослые особи которого являются всеядными с преобладанием растительноядности (Киселева, 2004). Третье место по численности занимают детритофаги (2,5\%), далее следуют плотоядные $(1,5 \%)$ и полифаги $(0,5 \%)$. Численность плотоядных и полифагов незначительна, что отражает, вероятно, их меньшую связь с ядром консорции.

Известно, что большинство черноморских полихет относится к детритоядным животным (Киселева, 2004). Значительная часть видов таксоцена полихет консорции рапаны также является детритофагами, однако по численности полихет трофическая структура таксоцена иная: детритофаги занимают только третье место, существенно уступая фильтраторам.

Для фильтраторов, которые нуждаются в твёрдом субстрате, рапана - это едва ли не единственная естественная возможность расширить своё присутствие в биотопе рыхлых грунтов. Проникновение в зону развития рыхлых грунтов растительноядных или преимущественно растительноядных полихет, а также видов, которые питаются животными, обитающими на макрофитах, также связано с $R$. venosa, которая является благоприятным субстратом для развития водорослей (Bondarev \& Milchakova, 2018).

Распределение по глубинам. Бо́льшая часть полихет консорции приурочены к глубинам 2-10 м. Спирорбины J. heterostropha были обнаружены на глубине от 0,5 до 23 м, и только серпулиды $S$. triqueter присутствовали на рапане от 0,5 м до максимальной глубины отбора проб 40 м (табл. 2).

Наиболее разнообразный видовой состав полихет в Чёрном море наблюдается на глубине $10-50$ м (Киселева, 2004). Бо́льшая часть видов полихет консорции $R$. venosa обнаружена на глубинах от 2-3 до 6-10 м (табл. 2). Ранее показано, что обилие водорослей и беспозвоночных вдоль градиента глубин в значительной мере определяется динамическими характеристиками водной среды (Бондарев и Ревков, 2017a, b, 2018 ; Бондарев и Бондаренко, 2019 ; Bondarev \& Milchakova, 2018). На прибрежных скалах динамика водных масс препятствует развитию водорослей и подвижных форм бентоса. На глубинах до 2 м песчаные грунты обладают высокой подвижностью и воздействуют угнетающе на развитие эпибентоса. Это в полной мере относится и к полихетам консорции, особенно к видам, связанным с водорослями топически и трофически. Так, $P$. dumerilii и $N$. zonata встречаются от 0 до 30 м, но в массовом количестве обитают на макрофитах, произрастающих на глубине 3-15 м (Киселева, 2004). На глубинах 2-10 м фотические условия развития водорослей наиболее благоприятны. Динамика вод, особенно в условиях бухт, на этих глубинах не препятствует оседанию личинок и жизнедеятельности молоди и взрослых особей на поверхности раковин рапаны. Не менее важным обстоятельством является то, что именно к этому диапазону глубин приурочены скопления $R$. venosa, выполняющей функцию ядра консорции. В летний период, когда рапана нерестится и активно питается, она мигрирует на мелководье, где и создаёт скопления (Bondarev, 2014). 
Седентарные виды, для которых основным лимитирующим фактором служит наличие/отсутствие твёрдого субстрата, были обнаружены в широком диапазоне глубин. Спирорбина J. heterostropha встречалась от глубины 0,5 до 23 м, и только серпулида S. triqueter присутствовала на рапане до максимальной глубины отбора проб (40 м), при минимальной глубине 0,5 м (табл. 2).

Заключение. В консорции $R$. venosa представители класcа Polychaeta являются таксономически наиболее разнообразной группой бентосных беспозвоночных: 9 отрядов, 15 семейств, 31 вид.

Таксоцен полихет, консортных рапане, представляет три биогеографические группы: аборигенные виды средиземноморско-атлантического генезиса, эндемики Чёрного моря и современные виды-вселенцы различного географического генезиса. Первая группа преобладает (84 \%), но вклад двух других групп достаточно представителен (10 и 6 \% соответственно).

Полихеты связаны с консорцией $R$. venosa топически и трофически и являются важным её компонентом. Они занимают первое среди таксономических групп место по встречаемости и численности в консорции рапаны.

Polychaeta присутствуют в консорции во всём диапазоне глубин обитания $R$. venosa, но большинство видов обнаружены на глубинах 2-10 м, к которым приурочены скопления рапаны и где существуют наиболее благоприятные условия для развития водорослевых обрастаний на её поверхности.

На песчаной $R$. venosa обнаружен 31 вид, а на скальной -5 видов. Встречаемость и численность полихет на песчаной рапане в большинстве районов исследований также выше, чем на скальной рапане.

В консорции рапаны многие виды полихет находят благоприятные условия для жизнедеятельности и получают дополнительные возможности для распространения на шельфе Чёрного моря.

Работа выполнена в рамках государственного задания ФИЦ ИнБЮМ по теме «Закономерности формирования и антропогенная трансформация биоразнообразия и биоресурсов Азово-Черноморского бассейна и других районов Мирового океана» (№ гос. регистрации 121030100028-0).

Благодарность. Авторы признательны анонимным рецензентам за конструктивные замечания и рекомендации, следование которым повысило качество публикации.

\section{СПИСОК ЛИТЕРАТУРЫ / REFERENCES}

1. Болтачева Н. А., Ковалёва М. А., Макаров М. В., Бондаренко Л. В. Многолетние изменения макрофауны скал в зоне верхней сублиторали у Карадага (Чёрное море) // 100 лет Карадагской научной станции им. Т. И. Вяземского : сборник научных трудов / под ред. А. В. Гаевской, А. Л. Морозовой. Симферополь : Н. Оріанда, 2015. С. 530-548. [Boltachova N. A., Kovaleva M. A., Makarov M. V., Bondarenko L. V. Macrofauna on the rocks longterm changes in the upper subtidal zone of Karadag (the Black Sea). In: 100 years of the T. I. Vyazemsky Karadag Scientific Station : issue of scientific papers. A. V. Gaevskaya, A. L. Morozova (Eds). Simferopol : N. Orianda, 2015, pp. 530-548. (in Russ.)]

2. Болтачева Н. А., Лисицкая Е. В., Лебедов- ская М. В. Новый для Черного моря вид полихет Hydroides dianthus (Verrill, 1873) (Polychaeta: Serpulidae) из прибрежных вод Крыма // Морской экологический журнал. 2011. T. 10, № 2. C. 34-38. [Boltachova N. A., Lisitskaya E. V., Lebedovskaya M. V. New species Hydroides dianthus (Verrill, 1873) (Polychaeta: Serpulidae) from the coastal waters of Crimea (the Black Sea). Morskoj ekologicheskij zhurnal, vol. 10, no. 2, pp. 34-38. (in Russ.)]

3. Бондарев И. П. Морфогенез раковины и внутривидовая дифференциация рапаны Rapana venosa (Valenciennes, 1846) // Ruthenica. 2010. T. 20, № 2. C. 69-90. [Bondarev I. P. Shell morphogenesis and intraspecific differentiation of $R a$ pana venosa (Valenciennes, 1846). Ruthenica, 2010, vol. 20, no. 2, pp. 69-90. (in Russ.)] 
4. Бондарев И. П. Структура популяций Rapana venosa (Gastropoda, Muricidae) Севастопольских бухт (Чёрное море) // Морской биологический журнал. 2016. T. 1, № 3. C. 14-21. [Bondarev I. P. Structure of Rapana venosa (Gastropoda, Muricidae) population of Sevastopol bays (the Black Sea). Morskoj biologicheskij zhurnal, 2016, vol. 1, no. 3, pp. 14-21. (in Russ.)]. https://doi.org/10.21072/mbj.2016.01.3.02

5. Бондарев И. П., Ревков Н. К. Консорты брюхоногого моллюска Rapana venosa (Valenciennes, 1846) в северной части Чёрного моря. Часть I: Porifera, Cnidaria, Bryozoa, Chordata // Морской биологический журнал. 2017a. T. 2, № 2. C. 20-33. [Bondarev I. P., Revkov N. K. Consorts of gastropod Rapana venosa (Valenciennes, 1846) in the Northern Black Sea. Part I: Porifera, Cnidaria, Bryozoa, Chordata. Morskoj biologicheskij zhurnal, 2017a, vol. 2, no. 2, pp. 20-33. (in Russ.)]. https://doi.org/10.21072/mbj.2017.02.2.02

6. Бондарев И. П., Ревков Н. К. Консорты брюхоногого моллюска Rapana venosa (Valenciennes, 1846) в северной части Чёрного моря. Часть II: Mollusca (Polyplacophora, Bivalvia) // Морской биологический журнал. 2017b. T. 2, № 3. C. 12-22. [Bondarev I. P., Revkov N. K. Consorts of gastropod Rapana venosa (Valenciennes, 1846) in the Northern Black Sea. Part II: Mollusca (Polyplacophora, Bivalvia). Morskoj biologicheskij zhurnal, 2017b, vol. 2, no. 3, pp. 12-22. (in Russ.)]. https://doi.org/10.21072/mbj.2017.02.3.02

7. Бондарев И. П., Ревков Н. К. Консорты брюхоногого моллюска Rapana venosa (Valenciennes, 1846) в северной части Чёрного моря. Часть III: Mollusca (Gastropoda) // Морской биологический журнал. 2018. Т. 3, № 1. С. 23-34. [Bondarev I. P., Revkov N. K. Consorts of gastropod Rapana venosa (Valenciennes, 1846) in the Northern Black Sea. Part III: Mollusca (Gastropoda). Morskoj biologicheskij zhurnal, 2018, vol. 3, no. 1, pp. 23-34. (in Russ.)]. https://doi.org/10.21072/mbj.2018.03.1.03

8. Бондарев И. П., Бондаренко Л. В. Консорты брюхоногого моллюска Rapana venosa (Valenciennes, 1846) в северной части Чёрного моря. Часть IV: Arthropoda // Морской биологический журнал. 2019. Т. 4, № 2. С. 11-22.
[Bondarev I. P., Bondarenko L. V. Consorts of gastropod Rapana venosa (Valenciennes, 1846) in the Northern Black Sea. Part IV: Arthropoda. Morskoj biologicheskij zhurnal, 2019, vol. 4, no. 2, pp. 11-22. (in Russ.)]. https://doi.org/10.21072/mbj.2019.04.2.02

9. Виноградов К. А. К фауне кольчатых червей (Polychaeta) Чёрного моря // Tруды Карадагской биологической станции. 1949. Вып. 8. C. 3-84. [Vinogradov K. A. K faune kol'chatykh chervei (Polychaeta) Chernogo morya. Trudy Karadagskoi biologicheskoi stantsii, 1949, iss. 8, pp. 3-84. (in Russ.)]

10. Виноградов К. А., Лосовская Г. В. Tun кольчатые черви - Annelida // Определитель фауны Чёрного и Азовского морей. Киев : Наукова думка, 1968. Т. 1 : Свободноживущие беспозвоночные. C. 251-405. [Vinogradov K. А., Losovskaya G. V. Tip kol'chatye chervi - Annelida. In: Opredelitel' fauny Chernogo i Azovskogo morei. Kyiv : Naukova dumka, 1968. Vol. 1 : Svobodnozhivushchie bespozvonochnye, pp. 251-405. (in Russ.)]

11. Гаевская А. В., Лебедовская М. В. Паразиты и болезни гигантской устрицы в услови$я$ ях культивирования. Севастополь : ЭКОСИГидрофизика, 2010. 218 с. [Gaevskaya A. V., Lebedovskaya M. V. Parasites and Diseases of the Giant Oyster (Crassostrea gigas) in Aquaculture. Sevastopol : EKOSI-Gidrofizika, 2010, 218 p. (in Russ.)]

12. Емельянов И. Г., Комиссарова М. С., Марченко В. С. Консортивные связи инвазионного вида гастропод Rapana venosa (Valenciennes, 1846) на шельфе Черного моря (Консортивні зв'язки інвазійного виду гастропод Rapana venosa (Valenciennes, 1846) на шельфі Чорного моря) // Екологія та ноосферологія. 2010. T. 21, № 3-4. C. 92-97. [Emel'yanov I. G., Komisarova M. S., Marchenko V. S. Consorting correlation of the invasive species Rapana venosa (Valenciennes, 1846) in the shelf area of the Black Sea. Ekologiya ta noosferologiya, 2010, vol. 21, no. 3-4, pp. 92-97. (in Ukr.)]

13. Зернов С. А. К вопросу об изучении жизни Чёрного моря // Записки Императорской академии наук. 1913. Т. 32, № 1.299 с. [Zernov S. A. K voprosu ob izuchenii zhizni Chernogo morya. Zapiski Imperatorskoi akademii nauk, 1913, vol. 32, no. 1, 299 p. (in Russ.)] 
14. Киселева М. И. Многощетинковые черви (Polychaeta) Чёрного и Азовского морей. Апатиты : Изд-во Кольского науч. центра РАН, 2004. 409 c. [Kiseleva M. I. Mnogoshchetinkovye chervi (Polychaeta) Chernogo i Azovskogo morei. Apatity : Izd-vo Kol'skogo nauch. tsentra RAN, 2004, 409 p. (in Russ.)]

15. Лисицкая Е. В., Болтачева Н. А., Лебедовская М. В. Новый для фауны Украины вид Polydora websteri Hartman, 1943 (Polychaeta: Spionidae) из прибрежных вод Крыма (Чёрное море) // Морской экологический журнал. 2010. T. 9, № 2. C. 74-80. [Lisitskaya E. V., Boltachova N. A., Lebedovskaya M. V. New Ukrainian fauna species Polydora websteri (Hartman, 1943) (Polychaeta: Spionidae) from the coastal waters of Crimea (Black Sea). Morskoj ekologicheskij zhurnal, 2010, vol. 9, no. 2, pp. 74-80. (in Russ.)]

16. Хлебович В. В. Многощетинковые черви Nereididae морей России и сопредельных вод. Многощетинковые черви. Т. 3. Фауна России и сопредельных стран. Санкт-Петербург : Наука, 1996. 224 с. [Khlebovich V. V. Polychaetes of the Family Nereidae of the Russian Seas and Adjacent Waters. Polychaetous Annelids. Vol. III. Fauna of Russia and Neighboring Countries. Saint Petersburg : Nauka, 1996, 224 p. (in Russ.)]

17. Чухчин В. Д. Функциональная морбология рапаны. Киев : Наукова думка, 1970. 138 c. [Chukhchin V. D. Funktsional'naya morfologiya rapany. Kyiv : Naukova dumka, 1970, 138 p. (in Russ.)]

18. Bick A. Polychaete communities associated with gastropod shells inhabited by the hermit crabs Clibanarius erythropus and Calcinus tubularis from Ibiza, Mediterranean Sea. Journal of the Marine Biological Association of the United Kingdom, 2006, vol. 86, iss. 1, pp. 83-92. https://doi.org/10.1017/S0025315406012884

19. Bondarev I. P. Dynamics of Rapana venosa (Valenciennes, 1846) (Gastropoda: Muricidae) population in the Black Sea. International Journal of Marine Science, 2014, vol. 4, art. no. 4, pp. 46-60.

20. Bondarev I. P., Milchakova N. A. Macroalgal fouling of shells of Rapana venosa (Valenciennes,
1846) (Gastropoda, Muricidae) in the Northern Black Sea. International Journal of Marine Science, 2018, vol. 8, art. no. 15, pp. 127-137.

21. Çinar M. E., Dağli E., Kurt-Şahin G. Checklist of Annelida from the coasts of Turkey. Turkish Journal of Zoology, 2014, vol. 38, no. 6, pp. 734-764. https://doi.org/10.3906/ zoo-1405-72

22. Giangrande A., Delos A. L., Musco L., Lucciano M., Pierri C. Polychaete assemblages of rocky shore along the South Adriatic coast (Mediterranean Sea). Cahiers de Biologie Marine, 2004, vol. 45, no. 2, pp. 85-95. https://doi.org/10.21411/CBM.A.E423CFF2

23. World Polychaeta database. Spirorbis pusilla Rathke, 1837 // World Register of $\mathrm{Ma}$ rine Species / G. Read, K. Fauchald (Eds). 2019. URL: http://www.marinespecies.org/ aphia.php? $=$ =taxdetails \&id=131234 (accessed on: 26.01.2020).

24. Savini D., Castellazzi M., Favruzzo M., OcchipintiAmbrogi A. The alien mollusk Rapana venosa (Valenciennes, 1846; Gastropoda, Muricidae) in the northern Adriatic Sea: Population structure and shell morphology. Chemistry and Ecology, 2004, vol. 20, iss. sup1, pp. 411-424. https://doi.org/10.1080/02757540310001629242

25. Serrano A., San Martín G., López E. Ecology of Syllidae (Annelida: Polychaeta) from shallow rocky environments in the Cantabrian Sea (South Bay of Biscay). Scientia Marina, 2006, vol. 70, no. S3, pp. 225-235. https://doi.org/10.3989/scimar.2006.70s3225

26. Streftaris N., Zenetos A. Alien marine species in the Mediterranean - the 100 'Worst Invasives' and their impact. Mediterranean Marine Science, 2006, vol. 7, no. 1, pp. 87-118. https://doi.org/10.12681/mms. 180

27. Sun Y., Wong E., Keppel E., Williamson J. E., Kupriyanova E. K. A global invader or a complex of regionally distributed species? Clarifying the status of an invasive calcareous tubeworm Hydroides dianthus (Verrill, 1873) (Polychaeta: Serpulidae) using DNA barcoding. Marine Biology, 2017, vol. 164, iss. 1, art. no. 28 (12 p.). https://doi.org/10.1007/s00227-016-3058-9 


\title{
CONSORTS OF GASTROPOD RAPANA VENOSA (VALENCIENNES, 1846) IN THE NORTHERN BLACK SEA. PART V: ANNELIDA (POLYCHAETA)
}

\section{P. Bondarev and N. A. Boltachova}

\author{
A. O. Kovalevsky Institute of Biology of the Southern Seas of RAS, Sevastopol, Russian Federation \\ E-mail: igor.p.bondarev@gmail.com
}

The study of Annelida (Polychaeta) taxocene - epibionts of the invasive gastropod Rapana venosa - continues the cycle of publications describing the composition of the consortium of the largest gastropod of the Black Sea benthos. $R$. venosa consortium is still a poorly investigated and unaccounted component in the structure of the Black Sea shelf biocenoses. The aim of this work is to study the complex of polychaetes of $R$. venosa consortium. The objectives of this stage are as follows: compiling a list of Annelida (Polychaeta) taxa - rapa whelk epibionts; studying taxocene biogeographic and trophic structure; and analyzing ecological relationships of polychaetes with the consortium core. To study the consort community of rapa whelk, sampling was conducted in seven areas of the northern Black Sea: 1 - Mamaia, Romania; 2 - northwestern Black Sea, Crimea offshore; 3 - Sevastopol; 4 - Alupka; 5 - Yalta - Alushta; 6 - Karadag; 7 - Kerch Strait. In the coastal area down to a depth of $15 \mathrm{~m}, R$. venosa was sampled totally using surface-supplied diving equipment; in the deeper-water area (up to $40 \mathrm{~m}$ ), samples were taken with an "Ocean-50" bottom grab from the board of the RV "Professor Vodyanitsky". Each rapa whelk specimen (sample) was placed in a separate plastic bag, with the indication of the area, depth, and biotope. In total, 2,411 samples were taken and analyzed: 977 - rock rapa whelks and 1434 -sand rapa whelks. $R$. venosa shell coverage with epibionts (fouling intensity) was determined as a percentage of the total area of the outer shell surface. Polychaeta taxocene of $R$. venosa consortium includes 31 species representing 31 genera of 15 families of 2 subclasses. Most species (18) belong to Errantia, and half of them are representatives of the families Nereididae and Syllidae. Sedentaria includes 13 species; by the largest number of species (4), the family Serpulidae is represented. Polychaeta taxocene of $R$. venosa consortium is represented by three biogeographic groups: native species of the Mediterranean-Atlantic genesis (84 \%), the Black Sea endemics (10\%), and recent invaders of various geographical genesis $(6 \%)$. On sand rapa whelk, 31 Polychaeta species were found; on rock rapa whelk, only 5 species were recorded. The indicators of Polychaeta fauna development differ significantly by the depth and research area. The most diverse polychaetes are those in bays of Sevastopol (the area No. 3) at depths of 2-10 m; the maximum depth of Polychaeta finding (40 m) corresponds to the greatest depth of rapa whelk sampling. The area of shell coverage with polychaetes reaches $70 \%$; occurrence in several areas is up to $95 \%$. The maximum number of species found at a single rapa whelk specimen is 8; on average, 2-4 Polychaeta species are recorded at $R$. venosa individuals. Taxonomic diversity and abundance of polychaetes determine their significance in $R$. venosa consortium. Due to the invasive predatory mollusc $R$. venosa, polychaetes get additional opportunities for spread on the Black Sea shelf.

Keywords: consortium, Polychaeta, Rapana venosa, Black Sea, ecology, epibionts 